\title{
Effect of bran particle size on gastric emptying and small bowel transit in humans: a scintigraphic study
}

\author{
R Vincent, A Roberts, $M$ Frier, A C Perkins, I A MacDonald, R C Spiller
}

\begin{abstract}
Bran is an effective treatment for constipation but its use is often limited by heartburn and bloating. This study examined the effect of fine and coarse bran (15 g) on the gastric emptying and small bowel transit of a $325 \mathrm{kcal}$ rice test meal. Twelve healthy volunteers underwent a three way cross over study, ingesting the technetium-99m labelled rice meal with or without $15 \mathrm{~g}$ of indium-111m labelled fine or coarse bran, in random order. Serial scintigraphic images were obtained to define gastric emptying and colonic arrival of label. Compared with control values (99 (9) minutes) (mean (SEM)), the time to $50 \%$ gastric emptying was significantly delayed by coarse but not fine bran, being 121 (6) and 104 (9) minutes respectively, $\mathbf{p}<0.05, n=12$. Fundal emptying was unchanged but both brans seemed to increase the proportion of isotope in the antrum at 90 minutes. Small bowel transit was slightly faster with both bran types but in this study the difference was not significant. Both the bran and rice labels moved down the gut without significant separation. Fine bran causes less disturbance of gastric physiology than coarse bran.
\end{abstract}

(Gut 1995; 37: 216-219)

Keywords: gastric emptying, bran, fibre, motility, scintigraphy.

High fibre diets are widely advocated as effective treatments for constipation ${ }^{1-4}$ as well as metabolic disorders especially glucose intolerance $^{5}$ and obesity. ${ }^{6}$ Bran is one of the commonest and most effective ways of increasing dietary fibre intake but intake may be limited by adverse effects including heartburn and postprandial bloating. ${ }^{7}$ Bran, like many other sources of dietary 'fibre', delays gastric emptying of liquids ${ }^{8}$ and reduces postprandial hyperglycaemia. ${ }^{5}$ We have previously shown, however, using a similar test meal that both $15 \mathrm{~g}$ of coarse bran (particle size $2 \mathrm{~mm}$ ) and $15 \mathrm{~g}$ of inert, non-viscous $2 \mathrm{~mm}$ plastic particles delay gastric emptying to a similar degree while the viscous gelling agent, ispaghula does not. ${ }^{9}$ This suggested that the bran particle size might be an important factor in delaying gastric emptying.

The first aim of this study was to discover if grinding coarse bran to reduce its mean particle size from $2 \mathrm{~mm}$ to $<0.7 \mathrm{~mm}$ would change this effect. Using our gamma scinti- graphic technique also allowed us to examine whether the intragastric distribution of the meal was changed by the various forms of bran, as others have suggested that excessive antral filling may be associated with the sensation of bloating seen in functional dyspepsia. ${ }^{10} 11$

Our previous studies used ${ }^{99 \mathrm{~m}} \mathrm{Tc}$ labelled rice, leaving open the question of whether this label readily separated from the meal residue. A subsidiary aim of this study was to assess the performance of the ${ }^{99 \mathrm{~m}} \mathrm{Tc}$ rice label by separately labelling the bran with ${ }^{111} \mathrm{In}$ and comparing transit of the two labels down the gut.

\section{Methods}

Twelve healthy volunteers (seven male, five female, aged 19-23 years), free from gastrointestinal symptoms and taking no regular medication attended after an overnight fast on three occasions. Women were required to have a negative pregnancy test the day before study. The study was approved by Nottingham University Medical School Ethical Committee.

\section{STUDY PROTOCOL}

Two days before study subjects adhered to a $20 \mathrm{~g}$ fibre diet and avoided alcohol. On each study day they consumed one of three ${ }^{99 \mathrm{~m}} \mathrm{Tc}$ labelled rice meals, A, B, or C (Table I) using a modified Latin Square design to overcome any order effects. After dosing radioactive markers $\left(0.1 \mathrm{MBq}{ }^{99 \mathrm{~m}} \mathrm{TcDPTA}\right.$ soaked onto filter paper) were taped to the skin anteriorly where the mid-clavicular line met the right costal margin. Serial anterior and posterior 30 second scintigraphic images were then obtained for each isotope at $10,20,40$, and 60 minutes, at 30 minute intervals for the next 2.5 hours, and thereafter hourly until 11 hours after dosing, when subjects were allowed home. Apart from water, subjects had no further food during the study day.

\section{LABELLING}

\section{Rice meal}

The rice meal was labelled by mixing into a rice pudding $25 \mathrm{~g}$ of freshly cooked rice soaked in $\mathrm{Na}^{99} \mathrm{TcO}_{4}$ solution acidified with a few drops of $1 \mathrm{M} \mathrm{HCl}$. Acidified $\mathrm{SnCl}_{2}$ solution (1 $\mathrm{g} / \mathrm{l})$ was then added to coprecipitate ${ }^{99} \mathrm{~m} \mathrm{TcO}(\mathrm{OH})_{2+}$ with colloidal $\mathrm{Sn}(\mathrm{OH})_{4}$. After leaving the mixture for 20 minutes the supernatant was then decanted and the rice 
TABLE I Test meal

Meal $A$

$325 \mathrm{kcal}$

$220 \mathrm{~g}$ creamed rice pudding

$25 \mathrm{~g}$ rice labelled with $5.0 \mathrm{MBq}^{99 \mathrm{~m}} \mathrm{Tc}$

$25 \mathrm{~g}$ rice labelled with

$34 \mathrm{~g}$ Robinson's seedless raspberry jam

$100 \mathrm{ml}$ concentrated orange juice

Meal $\mathrm{B}=\mathrm{A}+14 \mathrm{~g}$ coarse bran labelled with $0.5 \mathrm{MBq}^{111} \mathrm{In}$

Meal $\mathrm{C}=\mathrm{A}+14 \mathrm{~g}$ fine ground bran labelled with $0.5 \mathrm{MBq}^{111} \mathrm{In}$

remaining washed with $4 \times 50 \mathrm{ml}$ of water. The final wash eluted $<3 \%$ label. Labelling efficiency varied between $45-65 \%$ and in each case the amount of rice added was adjusted to provide $5 \mathrm{MBq}{ }^{99 \mathrm{~m}} \mathrm{Tc}$ per aliquot.

\section{Bran}

Some $1.5 \mathrm{~kg}$ of wheat bran (Holland and Barret Health Foods, Hinkley, Leicestershire, UK) was uniformly mixed and about $300 \mathrm{~g}$ completely ground, using a Kenwood Executive food liquidiser (Kenwood, Wilton, Hants, UK), yielding a powder that passed through a $710 \mu \mathrm{m}$ sieve. This powder is referred to hereafter as fine bran. The unprocessed bran that had a particle size $>200$ $\mu \mathrm{m}$ was used for the coarse bran meal.

Labelling with ${ }^{111}$ In was achieved by adding $0.5 \mathrm{MBq}{ }^{111} \mathrm{InCl}_{2}$ in acidified solution to a phosphate buffer solution ( $\mathrm{pH} 6 \cdot 2$ ) and then adding $14 \mathrm{~g}$ of fine or coarse bran. At the buffer $\mathrm{pH}^{111} \mathrm{InCl}_{2}$ was rapidly hydrolysed to colloidal ${ }_{111} \operatorname{In}(\mathrm{OH})$, which adsorbed to the bran. Labelling efficiency was only $33-66 \%$ but once bound the link seemed stable as repeated washings eluted $<5 \%$ of bound label.

The stability of both labels in a simulated gastric fluid was tested by incubating both rice and bran in continuously stirred saline containing $3.2 \mathrm{~g} / \mathrm{l}$ pepsinogen (Sigma Chemicals, St Louis, Missouri) at $\mathrm{pH}$ ranging from $2-4$ for three hours. Under these conditions $80 \%$ (range $75-90 \%$ ) of the bran label and $78 \%$ $(82-68 \%)$ of the rice label remained bound at three hours confirming their suitability for our study in which gastric emptying was largely complete by three hours.

\section{ANALYSIS OF SCINTISCANS}

The radioactive markers over the hepatic region were used to align serial scans. A region of interest (ROI) programme was used to obtain total abdominal, total gastric, fundal, antral, and colonic counts for both isotopes. In each case the whole series of images was reviewed before outlining each organ. The gastric image was divided into antrum and fundus by drawing a line to bisect the angle created at the incisura. Where this was not

TABLE II Ratio ${ }^{111} \mathrm{In} /{ }^{99 \mathrm{~m}} \mathrm{Tc}$ in whole stomach during emptying at 0,60 , and 120 minutes

\begin{tabular}{llll}
\hline Bran type & 0 Minutes & 60 Minutes & 120 Minutes \\
\hline Fine & 1.00 & $0.85(0.13)$ & $0.92(0.04)$ \\
Coarse & 1.00 & $0.99(0.01)$ & $1.04(0.02)$
\end{tabular}

No significant difference from time 0 for either bran type at either 60 or 120 minutes. Data presented as mean (SEM). clear the line was drawn on the initial images to bisect the area of the gastric region of interest with a line running perpendicular to the axis of the stomach. Geometric mean counts were then calculated for each region from anterior and posterior counts corrected for background and decay.

Regional time activity curves were then constructed and gastric emptying assessed from time to $50 \%$ emptying of whole stomach $\left(T_{50} \mathrm{GE}\right)$ and also for fundus separately $\left(\mathrm{T}_{50} \mathrm{GE}_{\text {fundus }}\right)$. Similarly mouth to caecum transit was assessed from time to $50 \%$ colonic filling (MCTT). Small bowel transit was then calculated from the difference $\mathrm{MCTT}-\mathrm{T}_{50} \mathrm{GE}$. Intragastric distribution of the rice label was assessed by calculating the ratio of antral/fundal counts. The ${ }^{11} 1 \mathrm{In} /{ }^{99} \mathrm{~m} \mathrm{Tc}$ ratio at various times during emptying was computed, expressing each as a percentage of initial dose, giving a number close to unity, which permitted assessment of whether there was any significant separation of the two labels. Total exposure to ionising radiation amounted to $0.64 \mathrm{mSv}$.

\section{STATISTICS}

Non-parametric statistics were used, the Wilcoxon signed ranks test for paired comparisons, and the Spearman's rank correlation coefficient to assess correlation.

\section{Results}

All subjects successfully completed the three studies and in all cases clear images of the stomach and colon were obtained. Apart from mild headache there were no adverse reactions to the meals. Gastric images using the ${ }^{99 \mathrm{~m}} \mathrm{Tc}$ label were much superior to those obtained with ${ }^{111}$ In and only these permitted clear definition of the fundal and antral regions. There was no evidence of separation between the bran and rice label, the ${ }^{111} \mathrm{In} /{ }^{99} \mathrm{~m} \mathrm{Tc}$ ratio for the whole stomach remaining unchanged over the period of gastric emptying (Table II). We have therefore reported the times to half emptying of gastric and half filling of the colonic regions for the ${ }^{99 \mathrm{~m}} \mathrm{Tc}$ label (Table III) as our best estimates of meal transit.

Gastric emptying of ${ }^{99 \mathrm{~m}} \mathrm{Tc}$ from the whole stomach $\left(\mathrm{T}_{50} \mathrm{GE}\right)$ was linear, with minimal lag in all cases. Emptying from the fundus occurred initially more rapidly causing an initial increase in antral counts, which then stabilised as the rate of emptying from the pylorus increased to match the rate of transfer from fundus to antrum. Emptying of both meals from the fundus occurred at a similar

TABLE III Regional transit data

\begin{tabular}{|c|c|c|c|}
\hline & Control & Coarse bran & Fine bran \\
\hline \multicolumn{4}{|l|}{ Gastric } \\
\hline $\mathrm{T}_{50} \mathrm{GE}$ & $99(9)$ & $121(6)^{\star}$ & $104(9)$ \\
\hline $\mathrm{T}_{50} \mathrm{~T}_{5 \text { fundus }}$ & $36(6)$ & $32(4)$ & $33(5)$ \\
\hline Colon filling & $467(31)$ & $453(29)$ & $438(30)$ \\
\hline Small bowel & $368(28)$ & $333(26)$ & $334(28)$ \\
\hline
\end{tabular}




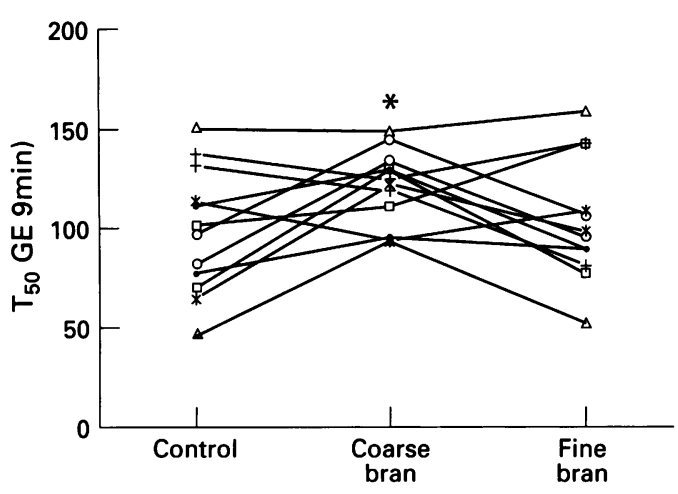

Figure 1: Effect of coarse or fine bran on $T_{50} G E$ (time to $50 \%$ emptying of test meals). Coarse but not fine bran significantly delayed emptying compared with control $\left({ }^{\star} p<0.05, n=12\right)$.

rate as assessed by $\mathrm{T}_{50} \mathrm{GE}_{\text {fundus }}$ but emptying of the whole stomach was significantly delayed by coarse but not fine bran (Table III, Fig 1). This implies that the delay occurred at the level of the antrum. The antral/fundal ratio of the ${ }^{99} \mathrm{~m}$ Tc label rose with time as emptying proceeded and label was transferred from fundus to antrum before emptying (Fig 2). When gastric emptying was half completed ( 90 mins), the antral/fundal ratios (mean (SEM)) were as follows: control $2 \cdot 7(1 \cdot 2)$, fine bran $3 \cdot 4$ $(1 \cdot 2)$, and coarse bran $3.9(2 \cdot 3)$. Although these differences failed to reach significance when the two bran study results were averaged giving a more reliable mean, $3 \cdot 7(1 \cdot 4)$, this value was significantly greater than control, $\mathrm{p}<0.05$.

There was no difference in time to $50 \%$ colonic filling for either bran preparation. As in previous studies small bowel transit tended to be accelerated by coarse bran but this effect was small and not significant $(p=0 \cdot 16)$ in this study.

Time to $50 \%$ colonic filling as assessed by the two isotope methods also correlated well

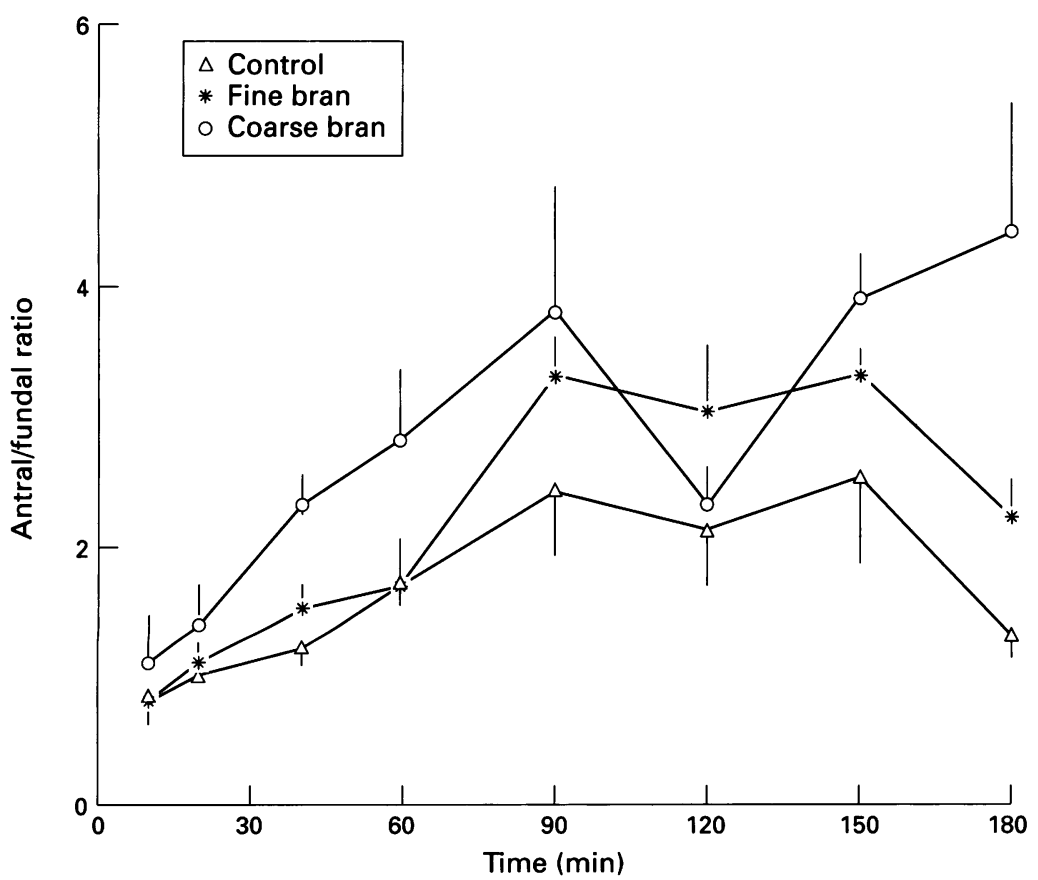

Figure 2: Ratio of counts in antrum/fundus versus time. There was a tendency for the ratio to be higher with both bran types, which was significant at 90 minutes $(p<0 \cdot 05, n=12$, see text). There was, however, no significant difference between the two bran preparations.
(Fig 3) showing that at all levels of the gut the bran and rice labels moved together.

\section{Discussion}

Both labels remained with the relevant meal components both in in vitro and in vivo studies. After ingestion both ${ }^{111} \mathrm{In}$ and ${ }^{99 \mathrm{~m}} \mathrm{Tc}$ passed down the gut together permitting clear imaging of the stomach and colon. The rice meal is presumably well homogenised during consumption forming a single phase, highly viscous chyme containing both liquid and solid components of the meal. Under these circumstances there is no apparent gastric sieving ${ }^{12}$ and little opportunity for label to become separated from the bulk of the meal.

These studies confirm earlier findings by ourselves $^{9}$ and others ${ }^{8}{ }^{9}$ that coarse bran delays gastric emptying. We have also shown that the main effect was at the level of the antrum with fundal emptying apparently unchanged.

The mechanism of action has been thought to be increased viscosity of gastric contents, ${ }^{13}$ which reduces pyloric flow. Increased viscosity reduces sedimentation of solids in liquids and thus impairs the ability of the antrum to preferentially empty liquids faster than solids (gastric sieving). ${ }^{14}$ Coarse bran has a greater water holding capacity than fine bran ${ }^{15}$ and when combined with our rice pudding meal there was an obvious increase in viscosity. Another obvious difference relates to particle size. The antropyloric mechanism seems to be able to selectively prevent the passage of particles greater than $2 \mathrm{~mm}$ diameter and may well have retarded the passage of coarse bran particles, whose size may have been increased further by adsorption of other meal components. This may account for our previous finding that inert, non-viscous plastic particles also delayed gastric emptying ${ }^{16}$ while the gelling agent ispaghula did not.

This delay in gastric emptying, together with a possible impairment of nutrient absorption in the intestine may delay the intragastric redistribution, which normally occurs as nutrients enter the duodenum. ${ }^{17}$ This could explain the tendency towards higher antral/fundal ratios seen with bran. Experimentally antral distension has been associated with a sensation of distension and bloating, ${ }^{18}$ which are of course common in patients consuming bran, as well as those with

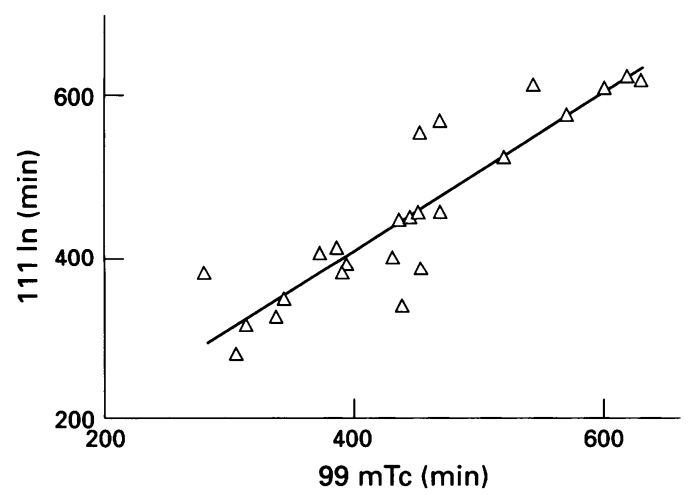

Figure 3: Correlation between colonic arrival of 50\% of rice $(99 \mathrm{~m} T \mathrm{c})$ and bran ( $\left.{ }^{11} \mathrm{In}\right)$ labels showing a close correlation, $\mathrm{r}=0 \cdot 9, n=24$. 
functional dyspepsia who have been shown to also show an increased antral/fundal ratio. ${ }^{10}$

Although this study used an identical meal to our previous study there was an important difference in subsequent feeding. In this study we permitted only water whereas previously we provided a sandwich lunch $(600 \mathrm{kcal})$ and afternoon tea four and seven hours after the test meal. This may well account for the fact that although the delay in gastric emptying seen was nearly identical ( 24 versus $22 \%$ ) the change in small bowel transit (29\% reduction, $\mathrm{p}<0.01$ ) was much more noticeable in the previous study ${ }^{9}$ than in this study ( $8 \%$ reduction, $\mathrm{p}=0 \cdot 16)$. This suggests that the accelerating effect of bran depends on its ability to enhance the propulsive effect of eating on ileal motility. This may be caused by water trapping or to a direct effect of bran particles on small bowel motility.

The most significant effect seen in both studies, the consistent delay in gastric emptying, may well account for the heartburn and bloating commonly noted as a side effect of bran containing meals. ${ }^{719}$ Although limiting its use in the treatment of constipation, this effect may be exploited for therapeutic benefit in a number of ways. Firstly, high fibre meals delay the onset of hunger and by enhancing satiety ${ }^{6}$ can be used as part of a weight reducing diet. ${ }^{20}$ Secondly, the delaying effect of fibre may also be exploited to reduce precipitous gastric emptying in the dumping syndrome ${ }^{21} 22$ and to reduce postprandial hyperglcaemia. ${ }^{5}$ This last effect may be beneficial in improving the control of blood sugar in diabetic patients by slowing the rate at which glucose containing foods enter the duodenum. Finally, as the laxative effect of fine bran is only marginally reduced compared with the coarse variety it may be reasonable to recommend fine bran in the treatment of constipation if compliance is limited by heartburn or bloating.

1 Harvey RF, Pomare EW, Heaton KW. Effect of increased dietary fibre on intestinal transit. Lancet 1973; i: 1279-80.

2 Wrick KL, Robertson JB, Van Soest PJ, Lewis BA, Rivers
JM, Roe DA, et al. The influence of dietary fiber source on human intestinal transit and stool output. F Nutr 1983; 113: $1464-79$.

3 Cummings JH, Hill MJ, Jenkins DJA, Pearson JR, Wiggins HS. Changes in fecal composition and colonic function due to cereal fiber. Am ₹ Clin Nutr 1976; 29: 1468-73.

4 Arffman S, Andersen JR, Hegnhoj J, Schaffalitzky de Muckadell OB, Mogensen NB, Krag E. The effect of coarse wheat bran in the irritable bowel syndrome. A double blind cross-over study. Scand $\mathcal{F}$ Gastroenterol 1985; 20: $295-8$.

5 Jenkins DJA, Wolever TMS, Leeds AR, Gassul MA, Haisman P, Dilawari JB, et al. Dietary fibres, fibre analogues, and glucose tolerance: importance of viscosity. $B M 7$ 1978; 1: 1392-4.

6 Haber GB, Heaton KW, Murphy D, Burroughs LF. Depletion and disruption of the dietary fibre. Effects on satiety, plasma-glucose, and serum insulin. Lancet 1977; ii: 679-82.

7 Chan PA, Read NW, Holdsworth CD. What is the benefit of coarse wheat bran in patients with irritable bowel syndrome? Gut 1984; 25: 168-73.

8 Grimes DS, Goddard J. Gastric emptying of wholemeal and white bread. Gut 1977; 18: 725-9.

9 McIntyre AS, Marshall R, Perkins AC, Spiller RC. Laxative effect of bran on small bowel transit: due to its particulate nature? [Abstract]. Gut 1993; 34 (suppl 4): S3

10 Troncon LEA, Bennett RJM, Ahluwalia NK, Thompson DG. Abnormal intragastric distribution of food during gastric emptying in functional dyspepsia patients. Gut 1994; 35: 327-32.

11 Hausken T, Berstdt A. Wide gastric antrum in patients with non-ulcer dyspepsia. Scand $\mathcal{F}$ Gastroenterol 1992; 27: 427-32.

12 Meyer JH, Elashoff GJ, Reedy T, Dressman J, Amidon G. Effects of viscosity and fluid outflow on postcibal gastric emptying of solids. Am f Physiol 1986; 250: G161-4.

13 Russel J, Bass P. Canine gastric emptying of fiber meals: influence of meal viscosity and antroduodenal motility. Am f Physiol 1985; 249: G662-7.

14 Meyer JH, Elashoff GJ, Reedy T, Dressman J, Amidon G. Effects of viscosity and fluid outflow on postcibal gastric emptying of solids. Am f Physiol 19086; 250: G161-4.

15 Brodribb AJM, Groves C. Effect of bran particle size on stool weight. Gut 1979; 19: 60-3.

16 Cummings JH, Branch W, Jenkins DJA, Southgate DAT, Houston H, James WPT. Colonic response to dietary fibre from carrot, cabbage, apple, bran, and guar gum. Lancet 1978; i: 5-9.

17 Houghton LA, Manganall YF, Read NW, Effect of incorporating fat into a liquid test meal on the relation between intragastric distribution and gastric emptying in human volunteers. Gut 1990; 31: 1226-9.

18 Azpiroz F, Malagelada J-R. Perception and reflex relaxation of the stomach in response to gut distension. Gastroenterology 1990; 98: 1193-8.

19 Meyer S, Calloway DH. Gastrointestinal response to oat and wheat milling fractions in older women. Cereal Chem 1977; 54: 110-9.

20 Di Lorenzo C, Williams CM, Hajnal F, Valenzuela JE. Pectin delays gastric emptying and increases satiety in Pectin delays gastric emptying and increases sa

21 Jenkins DJA, Gassul MA, Leeds AR, Metz G, Dilawari JB, Slavin B, et al. Effect of dietary fiber on complications of gastric surgery: prevention of postprandial hypoglycaemia by pectin. Gastroenterology 1977; 72: 215-7.

22 Welsh JD, Manion CV, Griffiths WJ, Bird PC. Effect of psyllium hydrophilic mucilloid on oral glucose tolerance and breath hydrogen in postgastrectomy patients. Dig Dis Sci 1982; 27: 7-12. 